

INTERNATIONAL JOURNAL OF RESEARCH -

GRANTHAALAYAH

A knowledge Repository

Arts

\title{
ART-RESEARCH IN MEMORY INSTITUTIONS: A BRIEF REVIEW OF THEIR RESOURCES FROM VISUAL-ARTS-RESEARCH PERSPECTIVE
}

\author{
Sudhir Kumar ${ }^{* 1}$ \\ ${ }^{* 1}$ Fine Arts, Aligarh Muslim University, INDIA
}

\begin{abstract}
Like the researches in many other fields major part of visual-arts-researches also depends greatly on such memory institutions as libraries and the archives. Besides these there are two other institutions of great importance - the art galleries and the museums, which serve as the most essential place where the visual art researchers may substantiate their research findings. Moreover these are such indispensable the places not only for the commons but also for the artresearchers who want to extend their scholarly contacts and become a part of the broader network of the knowledge and the practices in the area of their research interest. The paper taking a qualitative stance focuses on the availability and accessibility of those resources in these institutions which are especially helpful for the art researchers, and also discusses about what early preparations may be required before an access to these institutions, the ethics and the protocols which should be followed in order to get maximum out of them.
\end{abstract}

Keywords:

Archival Research, Art Galleries, Art Museums, Art-Research, Libraries, Research in Fine Arts, Research Methodology.

Cite This Article: Sudhir Kumar, "ART-RESEARCH IN MEMORY INSTITUTIONS: A BRIEF REVIEW OF THEIR RESOURCES FROM VISUAL-ARTS-RESEARCH PERSPECTIVE” International Journal of Research - Granthaalayah, Vol. 3, No. 10(2015): 84-99.

\section{INTRODUCTION}

Researches in many areas in Humanities and especially in Fine Arts relies to a great extent on Libraries, Archives, Museums, and Galleries (LAMG). Inclusively these institutions, the places where the human memories are stored, preserved and canonized into the cultures have recently been started being called as "memory institutions" (Pessach 2008). ${ }^{1}$ The "memory institutions" is a generic term coined in view of their increasingly inter-collaborative functioning in the recent times and their unprecedentedly growing virtual convergence due to interconnectivity at internet domains and the rapid digitization and uploading of their resources there (Constantinescu). These

\footnotetext{
${ }^{1}$ The first use of the term 'memory institutions' has been ascribed to the Swedish information scientist R. Hjerppe in 1994 (Robinson 2012).
} 
institutions can provide invaluable information for a researcher in general. But to avail the privileges of these institutions a researcher needs high level of expertise and dedication as these institutions themselves require high quality accessibility and visibility. They provide an important route for research in arts and humanities. They are the stocks of contemporary and historical evidences containing materials both in textual and physical forms that may substantiate a visualarts-research to a great extent. But they are never straight as a new researcher may expect. To use these materials a visual-arts-researcher has to make an intelligent selection of what is to be studied and what is to be excluded for saving her/his valuable time. So he has to closely analyze the substance of the relevant materials.

Though there may appear some similarities among Libraries, Archives, Museums, and Galleries regarding their organization and their role in providing information but there are vast differences in the nature of their holdings and the services they provide for both public and the researchers. For efficient research a researcher of visual arts must know about the organization and the mode of accessibility to these institutions. This will not only help him organize her/his steps in research but also save her/his precious time. It is also not always necessary that all of these institutions may be equally useful for her/him. It depends mostly upon the nature or area of her/his research. Therefore, before accessing any of these institutions he must program her/his schedule and fix the priorities according to the demands and nature of her/his research.

Using any of these institutions for research is in itself both an art and science. It is an art because to access the most appropriate required information or data requires high level of creativity, intelligence and a good conscience; and it is a science because it requires acute observation and a very precise interpretation thereof. In visual-arts-research mostly the artworks and the artists are talked about. But in certain cases artworks do not mean simply piece of art-objects well displayed in a gallery or in any public or private space, they may also be in intangible forms not easy to be discerned directly. Sometimes it may also be in the extended forms of art like- book illustrations, printed postcards, printed or handmade posters, painted scrolls on cloth, painted manuscripts, printed stamps, diary-sketches, decorated hand-fans, painted potteries and ceramics, ritual objects, votive figures and utensils, artistic calligraphy on a paper or palmyra surface, mystical diagrams, any separate artistic piece of architecture, etc. They may well be found also in the traditional sources such as museums, archives, and the collections in libraries, universities and other organizations. Finding and interpreting artworks requires inventiveness. A good visual-artsresearcher is the one who always has the knowledge of using these sources in advance and is respectful of the invaluable treasures held by these institutions. He must have the sensibility for careful handling of the materials provided by these sources. For taking care of the holdings and for the convenience of the users every such institution makes some set of rules which the users have to follow in order to avail their facilities. So a researcher delving into the research in fine and visual arts can make her/his feat easier if he is already well-versed with the rules of accessibility to the sources available in these institutions and the facilities provided by them.

The paper has been conceived due to the author's notice that, unlike the other fields of research, except a few written materials there is a paucity of adequate methodological literature on researches in visual arts especially how to use the afore-discussed institutions in relation to the fine art researches in India. Taking a discursive approach the aim of this research paper is to summarily highlight the facilities provided by these institutions especially those in galleries, museums and 
archives, that may prove to be indispensable for most of the thrust areas in the visual arts researches, and what inventiveness and preparation should be done by such researchers so that they may get maximum out of these. The discussion is mainly divided into four sections each giving an insight on the resources in Libraries, Galleries, Museums, and Archives respectively, and on what preparations he should make before reaching to avail those resources. Alongside there is also an attempt on providing a brief idea about the general protocols that such researchers must follow while doing research in these institutions.

\section{USING THE RESOURCES IN LIBRARIES}

Library is the foremost source of intellectualism of any kind. Today we are living in the age of Information and Communication Technology (ICT). There is a vast influx of information from all directions no matter whether we need it or not. It has become very easier to access any information from any part of the world. Internet is playing major role in this communication revolution. So internet search can be a hefty substitute for any of the aforesaid institution. But surely it can never replace library research. Libraries contain books and magazines (periodicals), hundreds or thousands of primary and secondary sources of information, as well as people who are trained to help and guide us through the research processes.

Before coming to a library a researcher must know what he wants to research. He may waste too many hours in the library if he does not have an idea what he plans to seek. So he must come prepared with tools. This means, he must bring a pen and paper and a large back-pack that can hold several books that he plans to take home. When we first come to a library it may be fruitful to talk to a librarian. Librarians have details and know very well about every in-and-out of the specific library and are trained to help the readers and researchers. It is foolish to ask simply, "Where is a particular book or a magazine?" They want to help us find tiny articles that are too buried and hidden to acknowledge. If we do not want to speak to the librarian, we can directly go to the computers as they have now replaced card catalogues. In fact the card catalogue system still exists, but now in a more accessible, legible format on the computer. We can go directly to the online-public-access-catalogues (OPAC). If we find anything confusing, we must ask a librarian for help. To search the location of the relevant books or any other material like journals, magazines or newspapers simply the subject is typed in as we do just in search engines on the internet. We can also search by 'author', 'topic', 'subject', 'title', or any 'combination thereof'. A list of books and publications comes on the screen. Then the catalogue number is written down so that we can find the books. A floor-plan is picked up. The map of the library can be very useful. What floor the books we have chosen are located on is found out. The first two letters of the book code corresponds with a type of book (Humanities, Sciences, Reserved, etc.) and a floor. After the floor is determined the book is searched by the catalogue number until we find it out.

Once the required books are located we need to decide which pages we require for our purpose from those. If there is issuing facility available we can get it issued otherwise we need to read it there and should take notes on a paper. It is always a good habit to write down all bibliographical information (author, publisher, published date, etc.) of the read book. However, many libraries also provide the copying facility. Some of them has copying machine in each stack. So a researcher can get the pages copied that he thinks purposeful. He must be sure that he has also copied the title page for all bibliographic information. It is always needed to document and cite the publication 
information in the thesis or in any research report. If the book has been got issued by the researcher he must be careful about its returning on the due date. Otherwise he can not only be charged with late fine but if it adds up over time he can even be banned from the certain libraries. Generally, library books are loaned for approximately two to five weeks, depending on the type of the book. Books can be returned through the 'Drop-Slot' installed outside the many libraries or can be handed over to a librarian inside the library.

\subsection{PERIODICALS}

Libraries are also the best place to find every periodical ever published for a period of over centuries and decades. Periodicals include journals, magazines, newspapers etc. To research a topic by magazine articles a researcher can use the 'Guide to Periodicals'. Generally it is often an enormous book index in each library for each year. It indexes every topic and person ever mentioned in any published magazine. Like the library catalogue of books, it helps to find a newspaper or magazine article on a person or idea. So to find the topic all the information given in the index for that subject is written down such as - Magazine, article title, article author, page number in magazine, volume, date, etc. Then this specific article can be located in the periodical section of the library. Most of these sections contain bound copies of the magazines for the recent years. For all magazines over a decade and farther in the past, one may have to use 'microfilms' to read. Because sometimes the volume is so grand that libraries put those magazines on microfilm to save space. If this is the case many libraries install a machine where the articles can be read from the microfilms. The libraries can even provide the facility to print out the pages from the microfilms at a slight cost per page. Again the researcher must remember to write down all 'contact and publication information' for each periodical he uses because he never know when he will need to locate it again. Furthermore, he as a token of gratitude to the author and also as a research ethic, should always document every source he uses in a research project.

\subsection{CATALOGUES AND INDEXES}

Catalogues are used to locate the books, periodicals or audiovisual items that are owned by a library. An Index is used to find information on a particular subject within a book or a magazine. For instance, the computer catalogue tells that the library owns 'Marg' magazine, but the researcher should need to use an index to know which issue of this magazine has an article on a particular subject, like 'Environmental Art, or the Ritual Arts'. Nowadays both catalogues and indexes can be accessed on computers.

\subsection{SUBJECT-HEADINGS AND KEYWORDS SEARCHING}

Before computers came into existence, all searching in library catalogues and indexes was based on Subject-Headings. Each book and periodical article was carefully examined and subject headings were selected to describe the main subjects of the book or article. The problem with subject headings is that people often are not sure of or are unable to come up to the exact subject heading that to be looked under. Also, librarians and indexers can only make a "limited number of subject headings" for identification of a book or article. The large catalogues or indexes become tricky to use for researchers as they work their way through many sub-headings. When computers were invented, a new method of searching appeared which is called - keyword searching. The 
Keyword searching makes it possible for the users to search for every word in the title of a book or every word in an entire magazine article. It often makes it very easier to find the wanted subject in a catalogue or index. But keyword searching also has disadvantages. While searching in a large database, it may retrieve many more references than we want to look through. When a word has more than one meaning, it may retrieve many citations on a subject of no interest ("Using The Library to Do Research" 2011). Overlooking this disadvantage keyword search is more efficient and time saving. Not only for the visual artists the library research, can be vital in all other researches too.

A rich library may also have data especially relevant to art-researches (such as documentaries on artists, films on art-performances or the interviews) in the forms of electronic media such asaudios and videos, or it may have access, to such audios and videos to other archives maintaining such resources, through the special links that probably might not be accessible to the commons. 2 So an art-researcher must ask about these. Sometimes the library may cater to these resources by borrowing from other institutions. Besides encouraging reading, providing books and maintaining digital resources, the libraries today, especially the public ones, are also involved in a wide range of activities such as- negotiating access to a diverse forms of information, "acting as a community space", associating to the other public and community services, and supporting digital participations. So the libraries can be a valuable place not only for a visual-arts researcher but others too to seek social contacts which can be useful for getting further sources of information on the areas of their respective researches (Smithies 2011a).

\section{RESEARCH IN A GALLERY}

Galleries are the places for mainly temporary exhibition of artworks, artefacts, antiquities or any other collection of items of contemporary or historical importance, e.g. Rabindra Bhavan of Lalit Kala Academy, New Delhi (India). Some of them also have halls for permanent display of their special collection of items or can especially be made for that purpose e.g. 'National Gallery of Modern Art (NGMA)' in India has been established for permanent display of Indian Modern and Contemporary artworks only. It collects artworks of contemporary Indian artists and makes a permanent display of some of their representative works. A gallery can be an autonomous institution or can be a unit of another institution such as museum, library or an academic institution. A frequent visit to an art gallery in itself is a very good source of information about the contemporary art for a researcher in visual/fine arts. Galleries are not just the place for display of items but it is also a place of cultural importance of a country or state. Therefore it can be a source of information not only for art researchers but also for researchers in various other disciplines like sociology, literature, philosophy, cultural study, anthropology, history, etc.

Nowadays many galleries promote researches on their collections by maintaining their own libraries, archives and print rooms and making these available to the public. Many of the galleries today get articles written on their collections by their own scholars or by hiring outsiders. They also arrange public lectures at regular basis by experts and eminent scholars on the collection and

\footnotetext{
${ }^{2}$ All these in general are collectively identified as the $e$-resources.
} 
the temporary exhibitions they organize. 3 They welcome scholars for doing researches on their resources, or may even appoint them permanently for the purpose. ${ }^{4}$ They employ conservationists and apply various techniques or use latest technologies to preserve the condition of their artworks. They are also engaged in research for inventing various new techniques of restoration and conservation of the artworks. They prepare catalogues and documentaries of their exhibitions and publish books and regular magazines on art and art history and also maintain their own archives of their special resources. In their archives they compile files of papers, drawings, sketchbooks, photographs, diaries, newspaper-cuttings and other printed ephemera. They can provide contacts of artists who at any time in past have exhibited their works there. They also conduct exchange programmes and various other activities in collaboration with other institutions. Even sometimes they provide various fellowships to promote research and study not only on the resources they have but also on the areas of contemporary importance in art and culture. So, an art gallery can be a vast reservoir of records of various events in art and art activities and therefore visiting an art gallery can be a great fortune for a visual-art researcher ("Research Resources").

\section{RESEARCH IN A MUSEUM}

Museums like galleries are also the places for exhibiting the collection of items and specimens. But the items they display may include a far wider range of varieties from any area of art, culture, history, or science. The role of museums has shifted over the years from only collecting and preserving items to a many other activities of education and research. The traditional notion of a museum was as "a centre of scholarship and curatorial expertise" but as the time has passed this has moved towards the more explicitly public-oriented goals, assisting people understand their culture, society, history and science in an entertaining way. Sharon Macdonald points out three main features of today's museums that show departure from the old notion of museology. They are - (i) the comprehension of "the meaning of museum objects as situated as contextual rather than inherent", (ii) the attention to commercialism and entertainment and (iii) the consideration of the visitor as an active agent. According to Paule Doucet the President of MINOM, ${ }^{5}$ museums are the 'agents of change' for a nation and society. So the museums today are more oriented towards a social role (Esmel-Pamies 2009). Playing as the social and recreational space museums are responsible for "shaping a sense of self and society through preserving cultural heritage and building understanding of other cultures" (Kumar 2014). Standing strong as a regional hub the museums today significantly have become a place where one can learn and have opportunities for developing personal knowledge and understanding (Smithies 2011b).

\footnotetext{
${ }^{3}$ For example, the art galleries in India Habitat Centre (IHC), New Delhi, the National Gallery of Modern Art (NGMA), India or the Vadhera Art Gallery, New Delhi and others besides regularly exhibiting the artworks also organizes seminars, lectures, on contemporary trends in art.

${ }^{4}$ For example, the Foundation for Indian Contemporary Art in collaboration of Vadhera Art Gallery both at New Delhi, give various research grants for researching on Indian Contemporary Art ("Research Fellowship" 2015). They also give grants to the art historians and curators for promoting research on contemporary arts ("Ila Dalmia FICA Research Grant" 2015). The Raza Art Foundation, New Delhi gives annual awards to the young artists and organizes panel discussions the documentations and recordings of which may be highly useful for the visual arts researchers on Contemporary India Art ("Activities" 2013).

${ }^{5}$ MINOM was founded in 1985 in Lisbon. It is an international forum of museology that was established to develop new ideas in the field and is aimed to act accordingly throughout the world.
} 
In this age of digital information and virtual experiences the notion of preserving objects tangibly may seem quite hackneyed, but the items the museums collect and preserve not only give a sense of experiencing our past they also investigate the techniques, methodologies, and philosophies, contained within or employed on the specimens which may reveal their importance in future too. These specimens tell the story of our evolution. They provide examples of items and adaptations produced in relation to the ways in which species, cultures, and places have responded to the environment from their origin to today. They unfold sagas of human progress in ways that other records often do not. Collections are "non-renewable resources", once lost, never be replenished. Through the preservation of collections, museums provide possibilities for future research and teaching. The museum characteristically is an interdisciplinary institution that provides opportunities for research and teaching across disciplines which may not easily possible in traditional academic institutions.

The International Council of Museums (ICOM) in 'Code of Ethics for Museums' (2006) delineates their function as "to maintain collections to hold them in trust for the benefit of society and its development. Museums must acquire, conserve, and exhibit collections, and educate the public about these collections". Developing an understanding of the cultural and environmental past based on collections is important not only in itself but critical for understanding the present and creating a viable future. A museum is a unique interface between the academic and research community and the wider public. The museums today are the major research and collecting institution in their own right. The museum supports the research by preserving in its collections unique items of "artistic, scientific, historic, and technological importance", protecting them for current and future research purposes. As an education resource for a diverse audience it collects, promotes researches, and disseminates the new knowledge and information about the natural and cultural heritage of local and related regions to a broader community (Ladkin et. al. 2010).

\subsection{ART MUSEUMS}

Today the term 'Museum' and 'Gallery' has become quite indistinguishable as many of the museums have specified their collection to the artworks only and as such many of them call themselves 'Art Museums' such as 'Museum of Modern Art (MOMA)' in Washington D.C. It collects artworks from the period after 1900 A.D. and also engaged in exhibiting the works of the contemporary artists. Art Museums are the places where paintings and sculptures, are the most commonly displayed items; however, installation art, decorative arts, textiles, costume, drawings, pastels, watercolours, collages, graphic prints, artists' monographs, photographs, etc. are also regularly shown. On the other hand there are some art galleries who besides arranging regular exhibitions of the artists of both period from contemporary and past have also some halls and spaces for permanent display of artworks and other collections. Many of the art museums maintain a collection of works on paper, drawings, pastels, watercolours, prints, and photographs but because of space and conservation reasons they typically do not display these articles permanently. Instead, they provide a dedicated study room located within the premises of the museum where these articles can be easily accessed. There are various forms of 20th century art, such as Land art and Performance Art, Site-specific Installation Art, Conceptual Art, Public Art, etc. which cannot exist inside a gallery or a museum. So the photographic or video records of these kinds of art are often shown/screened in them. Most of the contemporary museums and the art galleries usually have much larger collections of artworks and other artefacts than the samples of their exhibits on 
display. The rest are held in reserved collections on or off-site. Similar to an art gallery there has emerged the concept of sculpture garden or Sculpture Park which have sculptures mounted in an outdoor space. Nowadays sculpture installation has grown in popularity, so the temporary exhibits of sculptures are installed in open spaces during the events and festivals organized by the galleries and museums. So visiting art-museums regularly and exploring the records of such events can also be of great help for the visual-art researchers not only in their research work but developing links and contacts with the relevant artists and the other scholars working in the same area.

\subsection{DIFFERENCE BETWEEN MUSEUMS AND ART GALLERIES}

Sometimes it is very difficult to draw a sharp line between a Museum and an Art Gallery still some of the most conspicuous differences that can be observed between the two may be as following:

1) Generally the term 'Museum' is referred to as the collection of any kind of objects. For example, it may be a collection of scientific specimens (e.g. Museum of Vertebrate Zoology at Berkeley), wax figures (e.g. Madam Tussad Museum, Italy), artworks (e.g. Musée du Louvre, Paris), crafts (e.g. Crafts Museum, New Delhi), musical instruments (Sangeet Natak Akademi's Musical Instruments Gallery Museum, Delhi) or even a collection or arms (e.g. Arms Museum in Red Fort, New Delhi), whereas the term 'art gallery' denotes building space for an art-collection usually that of visual arts. However, the term gallery in general can refer to a section of a museum, such as for example the 'Portrait Gallery' in Victoria Memorial Museum in Kolkata.

2) Though the term 'art gallery' can be used interchangeably with 'museum' in some cases (as we saw in case of NGMA above), it also usually refers to a commercial art gallery, such as the 'Triveni Art Gallery' in Delhi. A commercial art gallery has the sole purpose of exhibiting artworks for their promotion and sale.

3) Some museums use neither term (museum or gallery) in their formal title, such as the 'Tate'. It is the federation of four museums and it functions through its various units both as a museum and an art gallery. ${ }^{6}$ Another example worth mentioning would be - Cité nationale de l'histoire de l'immigration in Paris or the Frick Collection.

4) Generally the non-profit institutions use the term 'museum' because the term broadens their mission and vision which in fact is not merely limited to display for sale like the profit making art galleries. They have the ambition of acquisition, care, study and diffusion of objects and their history.

5) These days there are high net worth art collectors - such as Charles Saatchi and Fancois Pinault, who operate their collections like museums for the public. ${ }^{7}$ Though some of them are for genuine interest in sharing their art collections with the public but others consider it as a strategy for making public relations and for promoting the marketing of artworks. Whatever is the intention of these art collectors, their collections would definitely be an invaluable source for research in visual or fine arts.

\footnotetext{
${ }^{6}$ The Tate consists of - (i) Tate Britain - Situated in London, it displays the collection of British art from 1500 to the present day; (ii) Tate Modern which is also in London, houses the Tate's collection of British and International Modern and Contemporary Art from 1900 to the present day; (iii) Tate Liverpool, which is of smaller scale but has the same purpose as Tate Modern. And (iv) Tate St Ives displays Modern and Contemporary Art produced by the artists of the related area ("Tate").

${ }^{7}$ The founders of Saatchi Gallery, London and Palazzo Grassi, Venice respectively.
} 
As we saw above, except the few conspicuous differences in nature of collections and the motive behind their display there is not much difference in the maintenance and the preservation of their articles, and keeping the records thereof in a museum and an art gallery. So the facilities they provide for a researcher are most often almost similar. Usually a museum also maintains a library of the publications based on its collections, and an archive that maintains the archaeological details of the findings and of the events organized by the museum. But the approach of doing research with museum articles is somewhat different from what that is done with an art gallery articles because a gallery article generally belongs to the contemporary period and it is most often an artwork; so comparatively it is easier to analyze these articles as the researcher has to consider for it only the contemporary socio-cultural context, the context to which the researcher belongs. But analyzing a museum article which may not always be an exact piece of art, or it may be a related article referring to the context for an artwork, or its related period, would be rather cumbersome. For analyzing a museum article the researcher has to come out of her/his contemporary sociocultural context and has to make a good understanding of the respective period of the that article. Then only he can successfully interpret the exact meaning and the motives behind the creation and form of that particular article.

\section{RESEARCH IN AN ARCHIVE}

An archive is a vast repository of "firsthand facts", data, and evidence from letters, reports, notes, memos, photographs, audio, video recordings, databases, official documents, etc. or to say, all the primary sources. ${ }^{8}$ Interestingly, knowingly or unknowingly we all have an archive even in our homes also. This is our personal archives: "a collection of materials that records important events from our family's history". All type of archives whether personal, state or national preserve items to serve as the proof of an event occurred, to explain how something happened, or for financial or sentimental reasons ("What's an Archives?"). Archives are created by a person, family, or an organization, public or private, in the conduct of their affairs. They are preserved because of the enduring value carried by the information they contain or as evidence of the rights and responsibilities of their creator (Pearce-Moses 2005).

Archives may be of a massive size such as the place that holds the records of national importance or it may be just smaller as a size of a room in a museum, library or in any other organization. So there are national archives, state archives, city archives, community archives, business archives, or an archive of a religious institution, and many more. There are archives for different types of government records, and also they are there which contain the personal records of individuals and organizations. If it is created within a publishing house it contains a published collection of scholarly papers, especially as a periodical. So there are also the archives that contain the personal papers of famous leaders (e.g. Abraham Lincoln, Nelson Mandela, etc.), authors (e.g. Rabindranath Tagore, etc.), scientists (e.g. Albert Einstein and Marie Curie), artists (e.g. Rembrandt, Van Gogh, Raja Ravi Verma, etc.) performers, spiritual leaders (Swami Vivekananda,

\footnotetext{
${ }^{8}$ Primary sources are contemporaneous to the events or later recalled by an eyewitness. It emphasizes the absence of intermediaries between the thing or events being studied and the reports of those. These sources are considered more accurate. Primary sources may include letters and diaries; government, church, and business records; oral histories; photographs, motion pictures, and videos; maps and land records; and blueprints. The contemporaneous Newspaper articles describing the events are also considered primary sources, although the reporter may have compiled the story from witnesses, rather than being an eyewitness. Gallery artefacts and the museum specimens are also considered as the primary sources.
} 
Aurobindo Ghosh, etc.) and business leaders (Jamshedji Tata, etc.), social activists (Raja Ram Mohan Roy, Martin Luther King, etc.), and others. Academic institutions like colleges and universities nearby also house a collection of authors' manuscripts, artists' works, and the notes of the professors and scholars who have been any how associated with these institutions. A temple, mosque or monastery can also hold the collections of their priests and devotees, which may prove to be of high cultural importance for the place they are situated and can proved to be an insightful resource for a researcher of arts, aesthetics and the religious studies.

\subsection{THE NATIONAL ARCHIVES OF INDIA (NAI)}

Archives are also created to make it sure that all important records will be available for research by the generations to come. In archives the original documents and records are kept in acid-free folders within acid-free boxes so that it may last long. They are kept in dark spaces with consistent temperature and humidity which helps to protect these valuable records from pests and unfavourable environmental conditions (Potter 2007). The National Archives of India (NAI) in New Delhi is the biggest archive in the country. The materials held by a National Archive are in the millions. The holdings are created by the government. The records held by the National Archives are official. The National Archives of India (NAI) is a repository of the non-current records of the Government of India. It was originally established with the name of 'Imperial Record Department (IRD)' in 1891, in Calcutta, by the British. It shifted to the present building in 1926. After independence, its name was changed to the 'National Archives of India'. It works in affiliation to the Office of the Department of Culture under Ministry of Culture, Government of India ("History"). It employs full and part-time workers to help facilitate the use of its holdings. The holdings of Indian National Archive are in English, Arabic, Hindi, Persian, Sanskrit, Modi, Urdu, etc. ${ }^{9}$ Apart from records on paper, it has records on palm leaf, birch bark, etc. The records are broadly of four categories: Public Records, Oriental Records,_Manuscripts ${ }^{10}$ and Private Papers ${ }^{11}$. These are the witnessing evidences of the activities of the later Mughals, the East India Company and British Rule and of the emergence and growth of the freedom struggle in India. They are the palimpsests of Indian social, political, economic and cultural life. Besides these there are Private Papers and more than "7500 microfilm rolls of records" gathered from around the countries like Canada, Germany, Malaysia, Myanmar, United Kingdom, United States, France, Russia etc. ("General Information about Holdings"). A national archive may have its regional units for acquisition and distribution of records and for the convenience of access for the public. This is why National Archive of India has a Regional Office at Bhopal and Record Centres at Bhubaneswar, Jaipur and Pudducherry.

Sometimes two archives may complement each other. This fact is very important for an archival research especially when we are doing research on biography of a personality such as some artist or an author. There may be a great possibility that her/his (the artist or the author) family archives and the archives of her/his friends or relatives may complement each other. The artist's or the

\footnotetext{
${ }^{9}$ The total holdings in the custody of National Archives of India comprise the following: $38,75,332$ files, 64,221 volumes, 1,10,332 maps and cartographic items, 3,601 Bills assented to by the President(s) of India, 1,065 Treaties, and 2,442 rare manuscripts ("General Information about Holdings").

${ }^{10}$ Manuscript is an unpublished document. It includes an author's draft of a book, article, or other work submitted for publication.

${ }_{11}$ Personal papers may be the non-official documents kept by an individual or the documents created, acquired, or received by her/him in the course of his or her affairs.
} 
author's family's archive may also complement a governmental archive. For instance, her/his family archive might contain the record of her/his birth but for its confirmation the researcher may confirm it by the original application for it in the National Archives (Potter).

\subsection{DIFFERENCE BETWEEN ARCHIVES AND LIBRARIES}

There seems quite similarity between a Library and an Archive as both the institutions hold repositories of print and non-print materials and make their collections available to the people. But there is a huge difference between libraries and archives in both respects - the types of materials they hold, and the way materials are accessed. Archives hold both published and unpublished materials. Materials in archives are often unique, specialized, or rare objects; very few of them exist in the other parts of the world, so they are the only ones of their kind. Once they gone can never be recreated. Such as a handwritten diary of a historic figure in an archive if somehow deteriorates is irreplaceable. But in a library when a book wears out can be replaced with a new copy. As the archival collections are unique the archivists strive to preserve for using them today and in future by generations of researchers. In Archives the researchers are supposed to handle the materials with care and protect them from physical damage and theft. They have even specific guidelines for it. In many cases there is an overlapping relation between archives and libraries. An archive may have library as a section within it, or an archive may be a unit within a library (Schmidt 2011a).

\subsection{INTERNET ARCHIVES}

With the advent and popularity of Internet over the past few decades, archiving has become easier and has made its way online. One of the most beneficial aspects of this type of archiving is that it takes up very little space. It can be used for storage by even an individual too. Internet archive also ensures that the information is safe as it evades the possibility of misplacing or getting destroyed by water and fire. Another beneficial aspect is its accessibility from any part of the world. Because of such reasons most of the institutions with physical archives have begun to digitize their holdings and make them available through Internet on virtual platforms called web portals ("Archival Research"). For example, the extensive web portal of the Indira Gandhi National Center for the Arts (IGNCA), New Delhi provides internet accessibility not only to its holdings of manuscripts and research papers, rare photographs in digitized formats but also one may go through the audio and video recordings of the events like cultural festivals, seminars, conferences, lecture series organized time to time by it ("Online Library Catalogue"). A web portal may be defined as:

- A web portal is most often one specially designed web page that brings information together from diverse sources in a uniform way. Usually, each information source gets its dedicated area on the page for displaying information (a portlet); often, the user can configure which ones to display ("Web Portal").

Thus, it has become far easier now for the researchers to collect information and access to the original sources by a few clicks or touches on her/his computer screen. A visual art researcher now can have even virtual or simulated visits to some of the great museums and galleries and analyze the exhibits by just sitting in his chair in front of her/his desktop. 


\subsection{VISITING AN ARCHIVE}

Many Archives today have launched their repository's website and on it they have posted the digitalized versions of their collections. So before visiting an archive it is better to go through these sites. The online catalogues are also available. If we have identified the material in the list but its digitized copy is not available on the website, then we will need to visit the archive in person. Archives have varying policies regarding their respective access. If we are far from the repository of the archive that we want to access truly will be a formidable task to reach it. In that case it would be a good idea to ask the archival staff, to determine whether the access to materials is obtainable without visiting the archives in person. Some archives can provide those through inter-library loan; 12 but this is rarely the case in primary or original documents. We can also ask from the archival staff, if the materials we want are available through libraries other than the repository at which we can easily access to find them out. We can also inquire for the scans or photocopies of the materials by post which may be provided with some fees. It can be a great option if an archive allows a research assistant to access materials on the behalf of the researcher or considers hiring a local graduate student or allows a friend living near the repository. The information we need can also be retrieved in a very short amount of time if an archival staff views the materials on our behalf and answers the reference questions. In case any of the aforesaid options is not possible then the researcher has to reach the archive in person. But as a precaution from uncertainties he must plan the visit in advance. For that the researcher must do the following arrangements:

[i] The researcher must inform the archival staff of the date(s) of her/his visit and the materials he likes to see; so that the staff can make it sure to provide the helping assistant and arrange the material in case if it is stored off-site before the stipulated date of visit. [ii] He must confirm the repository's scheduled visiting hours, entrance fees, limits on the amount of materials that may be requested at a time, any special closings, etc. The available options for accommodations, food, and transportation, etc. can also be examined in advance. The researcher must carefully review the guidelines for using materials at the archives. It may be available on the repository's website or can be asked to a staff member. [iii] He must also examine about the reproduction policies of the archives such as the fees and regulations for requesting photocopies, scans, conditions for photography, microfilming, and reproductions of photos and audio-visual materials, etc. [iv] There are some related organizations, and academic institutions which offer some research grants for such studies or even the archive may have the provisions for funding these, so a researcher must inquire about such opportunities. [v] As the archives mostly have primary materials and sometimes even in hand-written form, so their deciphering may take unexpectedly longer time. Therefore the researcher must follow some additional timeline. [vi] While working in an archive a researcher has very limited time so it must be utilized very efficiently. The prioritizing the interests would be very handy. On having any problem the help must be asked unhesitatingly from the attending staffs. They may be helpful for the researcher in familiarizing with the policies of archive. Though some archives may provide some research tools like pencils, magnifying glass, note-paper, etc. but it is always better to have own in advance. Generally the archival rooms are cool as the collections are stored in low temperature, so it is better to have a light sweater on before entering it.

\footnotetext{
${ }^{12}$ In such cases the archives would send such asked materials to the nearby library to the user where he could view or borrow them.
} 


\subsection{COMMON GUIDELINES IN ARCHIVAL REPOSITORIES AND THE READING- ROOM PROTOCOLS}

[i] Before entering the repositories of an archive the researchers are generally asked to complete some formalities like filling an application, registry card, online form, or they may ask to acquire a researcher card. The forms besides name, address and institutional affiliation include details about materials to be used, and a description of the research project. The photo IDs may be requested. In some of the archives a note of recommendation or special permissions before admitting the researcher is required. But these are for the security reasons. For the same reasons they may also ask for the removal of bags, valuable items and bulky outer-clothing. Archives don't allow foods and drinks because spills can damage the documents or can attract the insects that may infect the materials. [ii] In archives a researcher may have to fill variety of other forms for respective situations. They may be for specifying boxes or books, for requests for reproductions, or for requesting an unpublished material. These forms or slips require user's signature and they are for keeping track of the usage. They indicate that the signatory has read and understood the stipulations or conditions for use and is obliged for any discrepancy done by him/her during the usage. [iii] Only a pencil can be used for accidental marks if required any. It is better to mark with paper inserts provided. The archives may provide gloves for handling objects or photographs in order to protect those from the oils and other residues left by hands. Archives may provide other various specialized tools for careful handling of the materials such as book cradles. Care is also taken for the order and sequence of the materials, otherwise they may be considered missing and can cause inconvenience for the future researchers. [iv] Most of the archives don't prohibit using such digital devices like cameras, laptops, watches, but restrictions may exist in some cases. The materials may require permissions before they are reproduced as the lights used by cameras and scanners can cause damage or fade the text and images on the documents on account of their likely overexposure. There are usually some guidelines for using older stuffs as they are generally prone to be more fragile, yet in archives even the new materials are cared in their use so they remain available to the next generation of researchers. Copying can be done without injury to the material. And publishing any part from acquired reproductions also requires prior permission. So it must be kept in mind that supplying a reproduction by an archive is not an authorization to publish. And if the permission is granted on a material that has copyright vested in other individual or an organization; then the researcher has to seek the permission himself from its holder ("Gallery Archives: Information for Researchers" 2015). In cases such that the research in an archive becomes a source for publication, then the archive may request a copy of the publication. When a particular item is available in a surrogate format, researchers are provided only the surrogates (microfilms, digitized versions and photocopies etc.) so that the original could remain preserved ("Gallery Archives: Information for Researchers"). [v] While taking the notes the researcher must be heedful to the accuracy especially while researching with unpublished manuscripts or complicated archival materials and the full citations must be taken. It must include unique identification assigned to the materials by the archives such as the call number, collection title, box number, folder number and document details etc. It will help in retracing the material if needed in future. This will also be beneficial to later researchers will be able to find that material easily. While citing a correspondence, the name of the author as well as the receiver, and the date of receiving the letter, if known all are noted accurately and in correct format ("Gallery Archives: Information for Researchers"). 
It is the sign of a good researcher that if he finds any mistakes or omissions while researching in an archive and being an expert in that related area he can fill in some information gaps. He should point out those omissions to the archivists and should cite another authoritative source in support of the corrections if possible. Archives are the unique places where specialists come from all over the world. It is a great opportunity for a researcher if he makes contacts with other researchers. May be someone expert from the area can prove to be a fortune in her/his research. He should introduce himself to other researchers and should share her/his topic unhesitatingly (Schmidt 2011b).

\section{CONCLUSION}

The libraries, art galleries, museums and the archival bodies are the great repositories of knowledge. These are the places of the same importance to a researcher or a knowledge seeker as a devotional shrine is to a spiritual seeker. To get them established needs a great effort both in terms of time and money, and above all, they need invaluable efforts of the visionaries who have worked hard through the years and centuries to save the accumulated knowledge of the ages, and make it available for the future generations. So a responsible researcher is the one who sensibly utilizes these knowledge shrines not for fulfilling their own ambitions or to inflect her/his findings to satisfy a particular ideology but to add to them new knowledge and disseminate that in the forms which are the true representations of the truth and easily receptive to the society and masses. Only then the real purpose of these institutions, irrespective of the places that they may belong to, can be resolved in order for the betterment of the conditions of the world.

Though a visual art researcher has primarily to present before the world the true understanding of the arts and to reveal the inexpressible joy that is vibrating through those works no matter what period or place they come from. So s/he has not only more directly to engage with the artworks and the artists but to corroborate her/his views and observations, whether analytical or critical, these cultural seats of learning and arts will serve to a much extent.

\section{ACKNOWLEDGEMENTS}

This paper would not be possible without the wide-ranging insights on the research methods and the knowledge repositories from the faculty members, library-staffs of the university, the helping staffs at various galleries and the museums that the author has visited, and the invited resource persons and the participants at the interaction programmes and seminars attended by the author during the last few years. Author feels privileged of being in their enlightening aura as well as indebted to all of them for their illuminating discussions and invaluable suggestions that have since benefitted him greatly.

\section{REFRENCES}
[1] "Activities"
(2013).
The
Raza
Foundation.
Retrieved http://www.therazafoundation.org/activities.php accessed on Oct. 14, 2015.
[2] “Archival Research" (n. a.). Retrieved https://en.wikipedia.org/wiki/Archival_research accessed on Oct. 13, 2015. 
[3] Constantinescu, Nicolaie M. (n. a.). "When We Come Together: When Libraries, Archives, Museums and Galleries are Linked Together". Retrieved http://eprints.rclis.org/17566/1/When\%20we\%20come\%20together.pdf accessed on Oct. 17, 2015.

[4] Esmel-Pamies, Cinta (2009). Into the Politics of Museum Audience Research, Tate Encounters, pp. 5-6. Retrieved http://www2.tate.org.uk/tate-encounters/edition-5/CintaEsmel-Pamies-Into-the-Politics-of-Museum-Research.pdf accessed on Oct. 13, 2015.

[5] "Gallery Archives: Information for Researchers" (2015). National Gallery of Art, Washington, DC. Retrieved https://www.nga.gov/resources/gainfores.shtm accessed on Oct. 13, 2015.

[6] "General Information about Holdings" (n. a.). National Archives of India, Retrieved http://www.nationalarchives.nic.in/writereaddata/html_en_files/html/NAIH_Gen.html accessed on Oct. 14, 2015.

[7] "History" (n. a.). National Archives of India, Retrieved <http://www.nationalarchives.nic.in/ShowContent.aspx? uid $1=1 \&$ uid $2=1 \&$ uid $3=0 \&$ uid4 $=0>$ accessed on Oct. 14, 2015.

[8] ICOM Code of Ethics for Museums (2006). International Council of Museums. Retrieved <http://icom.museum/fileadmin/user_upload/pdf/Codes/code_ethics2013_eng.pdf> accessed on Oct. 13, 2015.

[9] "Ila Dalmia FICA Research Grant" (2015). Foundation for Indian Contemporary Art. Retrieved <http://www.ficart.org/ila-dalmia-fica-research-grant/> accessed on Oct. 14, 2015.

[10] Kumar, Sudhir (2014). "Indian Ritual Objects in Contemporary Museums and their Contextual Crisis”, Proceedings of National Seminar on Ancient and Spiritual Sciences (25-26 Oct.), organized by Center for Scientific Spirituality Studies, Dev Sanskriti Vishwavidalya, India; Bharti Publications, New Delhi, pp. 366-73. Retrieved $<$ https://drive.google.com/folderview?id=0B4-

dDhhgG4AeVWtYakdQQkg5Zmc\&usp=sharing_eil> accessed on Oct. 13, 2015.

[11] Ladkin, Nicola/Johnson, Eileen/Baker, Robert J./Chatterjee, Sankar (2010). The Use of Collections in Research and Teaching at The Museum of Texas, Tech University, UMACJ 3/2010, p. 134. Retrieved <http://edoc.hu-berlin.de/umacj/2010/ladkin127/PDF/ladkin.pdf> accessed on Oct. 13, 2015.

[12] “Online Library Catalogue" (n. a.). Indira Gandhi National Centre for the Arts (IGNCA). Retrieved <http://ignca.nic.in/kn_access_catalogue.htm> accessed on Oct. 14, 2015.

[13] Pearce-Moses, Richard (2005). The Glossary of Archival and Records Terminology, The Society of American Archivists, Chicago, pp. 30-33. Retrieved <http://files.archivists.org/pubs/free/SAA-Glossary-2005.pdf> accessed on Oct. 14, 2015.

[14] Pessach, Guy (2008). [Networked] Memory Institutions: Social Remembering, Privatization and its Discontents, p. 73. Retrieved <http://www.cardozoaelj.com/wpcontent/uploads/Journal\%20Issues/Volume\%2026/Issue\%201/pessach.pdf> accessed on Oct. 17, 2015.

[15] Potter, Lee A. (2007). What is an Archives? Retrieved http://files.archivists.org/advocacy/AAM/WhatIsAnArchives.pdf accessed on Oct. 14, 2015.

[16] "Research Fellowship" (2015). Foundation for Indian Contemporary Art. Retrieved <http://www.ficart.org/iladalmiaficaresearchgrant/> accessed on July 15, 2015. 
[17] "Research Resources", National Galleries of Scotland. Retrieved <https://www.nationalgalleries.org/visit/research-resources/> accessed on Oct. 14, 2015.

[18] Robinson, Helena (2012). "Digital Heritage, Remembering Things Differently: Museums, Libraries and Archives as Memory Institutions and the Implications for Convergence”, Museum Management and Curatorship Vol. 27, No. 4 (October), Routledge London, p. 415.

[19] Schmidt, Laura (2011a). Using Archives: A Guide to Effective Research, Society of $\begin{array}{lllll}\text { American Archivists } & \text { (SAA), } & \text { p. } & \text { Retrieved }\end{array}$ <http://www2.archivists.org/sites/all/files/UsingArchives_Final.pdf> accessed on Oct. 14, 2015.

[20] Schmidt, Laura (2011b). Using Archives: A Guide to Effective Research, Society of $\begin{array}{lllll}\text { American Archivists } & \text { (SAA), } & \text { p. } & \text { Retrieved }\end{array}$ <http://www2.archivists.org/sites/all/files/UsingArchives_Final.pdf> accessed on Oct. 14, 2015.

[21] Smithies, Rachel (2011a). A Review of Research and Literature on Museums and Libraries, Arts Council England, September, p. 46. Retrieved <http://www.artscouncil.org.uk/media/uploads/pdf/a_review_of_research.pdf> accessed on accessed on Oct. 13, 2015.

[22] Smithies, Rachel (2011b). A Review of Research and Literature on Museums and Libraries, Arts Council England, September, pp. 22-23. Retrieved <http://www.artscouncil.org.uk/media/uploads/pdf/a_review_of_research.pdf> accessed on accessed on Oct. 13, 2015.

[23] "Tate" (n. a.). Retrieved <http://www.tate.org.uk/visit> accessed on Oct. 13, 2015.

[24] “Using The Library to Do Research” (2011). Cecil W. Robins Library, Louisburg College. Retrieved <http://www.louisburg.edu/library/research.html> accessed on Oct. 13, 2015.

[25] "Web Portal". Wikipedia, The Free Encyclopedia. Retrieved <https://en.wikipedia.org/wiki/Web_portal>accessed on Oct. 13, 2015.

[26] “What's an Archives?" (n. a.). Retrieved <http://www.archives.gov/about/info/whats-anarchives.html> accessed on Oct. 13, 2015. 